OPEN ACCESS

Edited by:

Fan Jin,

Zhejiang University, China

Reviewed by:

Sana Jalal,

University of Sulaymaniyah, Iraq

Qifei Li,

Boston Children's Hospital and Harvard Medical School,

United States

*Correspondence:

Yingjun Xie

xieyjun@mail2.sysu.edu.cn

Dongmei Chen

chendm9090@163.com

Specialty section:

This article was submitted to Genetics of Common and Rare

Diseases,

a section of the journa

Frontiers in Genetics

Received: 18 June 2021

Accepted: 20 August 2021

Published: 30 September 2021

Citation:

Zhuang J, Zhang N, Wang Y, Zhang $\mathrm{H}$, Zheng $Y$, Jiang $Y, X$, Xie $Y$ and

Chen D (2021) Molecular

Characterization Analysis of Thalassemia

and Hemoglobinopathy in Quanzhou, Southeast China: A Large-Scale

Retrospective Study.

Front. Genet. 12:727233.

doi: 10.3389/fgene.2021.727233

\section{Molecular Characterization Analysis of Thalassemia and Hemoglobinopathy in Quanzhou, Southeast China: A Large-Scale Retrospective Study}

\author{
Jianlong Zhuang', Na Zhang', Yuanbai Wang', Hegan Zhang'2, Yu Zheng', \\ Yuying Jiang ${ }^{1}$, Yingjun Xie ${ }^{4,5 *}$ and Dongmei Chen ${ }^{6 *}$
}

\begin{abstract}
${ }^{1}$ Prenatal Diagnosis Center, Quanzhou Women's and Children's Hospital, Quanzhou, China, ${ }^{2}$ Department of Gynecology, Quanzhou Women's and Children's Hospital, Quanzhou, China, ${ }^{3}$ Research and Development Department, Yaneng BIOscience (Shenzhen) Co. Ltd., Shenzhen, China, ${ }^{4}$ Key Laboratory for Major Obstetric Diseases of Guangdong Province, Department of Obstetrics and Gynecology, The Third Affiliated Hospital of Guangzhou Medical University, Guangzhou, China, ${ }^{5}$ Key Laboratory of Reproduction and Genetics of Guangdong Higher Education Institutes, The Third Affiliated Hospital of Guangzhou Medical University, Guangzhou, China, ${ }^{6}$ Department of Neonatal Intensive Care Unit, Quanzhou Women's and Children's Hospital, Quanzhou, China
\end{abstract}

Background: There are limited reports available on investigations into the molecular spectrum of thalassemia and hemoglobinopathy in Fujian province, Southeast China. Here, we aim to reveal the spectrum of the thalassemia mutation and hemoglobinopathy in Quanzhou prefecture, Fujian province.

Methods: We collected data from a total of 17,407 subjects with the thalassemia trait in Quanzhou prefecture. Gap-PCR, DNA reverse dot blot hybridization, and DNA sequencing were utilized for common and rare thalassemia gene testing.

Results: In our study, we identified 7,085 subjects who were carrying thalassemia mutations, representing a detection rate of $40.70 \%(7,085 / 17,407)$. Among them, 13 different $\alpha$-thalassemia gene mutations were detected, with the most common mutation being _SEA (69.01\%), followed by $-\alpha^{3.7}$ (21.34\%) and $-\alpha^{4.2}$ (3.96\%). We also discovered $26 \beta$-thalassemia gene mutations, with the mutations of IVS-II-654 (C > T) (36.28\%) and CD41/42(-TCTT) (29.16\%) being the most prevalent. Besides, a variety of rare thalassemia variants were identified. Among them, the $-{ }^{\text {FlL }}, \beta^{\text {Malay }}$, $\beta^{I V S-1-130}$, and $\beta^{I V S-I I-672}$ mutations were identified in Fujian province for the first time. Additionally, we detected 78 cases of hemoglobinopathies, of which $\mathrm{Hb}$ Owari was the first reported case in Fujian province and $\mathrm{Hb}$ Miyashiro was the first case identified in the Chinese population.

Conclusion: Our study indicates that there is a diverse range of thalassemia mutations, and it also reveals the mutation spectrum of rare thalassemia and hemoglobinopathies in Quanzhou, Fujian province. It provides valuable data for the prevention and control of thalassemia in Southeast China.

Keywords: thalassemia, hemoglobinopathy, molecular spectrum, DNA sequencing, Southeast China 


\section{INTRODUCTION}

Thalassemia is a hereditary blood disorder caused by human globin gene synthesis disorders, of which $\alpha$ - and $\beta$-thalassemia are the most common genotypes (Weatherall, 2001). It most commonly occurs in Mediterranean countries, the Middle East, the Indian subcontinent, Southeast Asia, and China (Modell and Darlison, 2008; Weatherall, 2008). Thalassemia is mainly distributed in the southern regions of China, especially Guangdong, Guangxi, and Hainan provinces (Zhang et al., 2010; Li et al., 2014; Yao et al., 2014; Yin et al., 2014; He et al., 2018; Lu et al., 2021).

Fujian province, which is located in Southeast China, also displays a high prevalence of thalassemia (Xu et al., 2013; Huang et al., 2019; Zhuang et al., 2020a). Quanzhou prefecture has the largest population in Fujian and possesses high population mobility, which may have led to greater diversity and complexity of thalassemia gene mutations. Recently, more rare or novel thalassemia mutations have been identified in the Quanzhou region (Zhuang et al., 2019, 2020b). To date, no effective medical treatment for thalassemia intermedia or major has been developed. Fetuses with $\alpha$-thalassemia major usually die in utero or shortly after birth, and this condition also often leads to the mortality of the pregnant mother (Vichinsky, 2013). Fetuses with $\beta$-thalassemia major usually develop severe progressive anemia after 3-6 months and rarely survive past 5 years of age if not treated with a regular transfusion program and chelation therapy (Liaska et al., 2016). Therefore, thalassemia genetic detection before marriage or pregnancy, as well as prenatal diagnosis, is the only effective intervention to prevent the births of babies with thalassemia major or intermedia. However, there is very little knowledge on the genotypes of thalassemia, and there is a lack of information on the hemoglobinopathy mutation spectrum in the Quanzhou region.

This retrospective study was performed to analyze the spectrum of the thalassemia gene mutation and characterize the genotypes of rare thalassemia and hemoglobinopathy in Quanzhou prefecture. It aims to provide valuable reference data for the prevention and control of thalassemia in Southeast China.

\section{MATERIALS AND METHODS}

\section{Study Subjects}

A total of 17,407 subjects who were suspected of being thalassemia carriers were recruited at Quanzhou Women's and Children's Hospital between January 2013 and March 2021. The age of these subjects ranged from 1 to 67 years old. We performed thalassemia gene detection on all of the subjects who met the following inclusion criteria: (1) routine hematology examination showed abnormal mean corpuscular volume $(\mathrm{MCV})<82 \mathrm{fl} /$ or mean corpuscular hemoglobin $(\mathrm{MCH})<27 \mathrm{pg}$; (2) abnormal hemoglobin electrophoresis; (3) parents or siblings carried the thalassemia gene mutation; (4) at least one of the couple was identified as a thalassemia carrier.

\section{Hematological Analysis and Serum Ferritin Test}

Approximately $4 \mathrm{ml}$ of peripheral blood was collected from each subject and anticoagulated with EDTA- $\mathrm{K}_{2}$ for routine blood analysis and hemoglobin electrophoresis analysis. We performed routine blood detection on all of the subjects using an automated cell counter (Sysmex XS-1000i; Sysmex Co., Ltd., Kobe, Japan) and analyzed the hemoglobin components by hemoglobin electrophoresis (Sebia, Evry Cedex, France). Positive hematological screening was defined as an MCV of less than $82 \mathrm{fl}$ and/or an $\mathrm{MCH}$ concentration of less than $27 \mathrm{pg}$ and/or hemoglobin A2 (HbA2) levels greater than 3.4\% or less than $2.6 \%$ or an $\mathrm{Hb} \mathrm{F}$ value of more than $2.0 \%$. All patients with positive hematological analysis results underwent thalassemia gene testing.

For the serum ferritin test, approximately $3 \mathrm{ml}$ of peripheral blood was collected from the patients. Then, it was centrifuged at 3,500 rpm for $10 \mathrm{~min}$ to separate the serum. The serum ferritin test was performed with Siemens Healthcare

TABLE 1 | Distribution of $\alpha$-thalassemia genotypes in Quanzhou Prefecture.

\begin{tabular}{|c|c|c|c|}
\hline Genotypes & Cases & Frequency & Class \\
\hline$-S E A / \alpha \alpha$ & 3,427 & $70.17 \%$ & Common \\
\hline$-\alpha^{3.7 / \alpha \alpha}$ & 897 & $18.37 \%$ & Common \\
\hline$-\alpha^{4.2} / \alpha \alpha$ & 163 & $3.34 \%$ & Common \\
\hline$\alpha \alpha^{Q S} / \alpha \alpha$ & 100 & $2.05 \%$ & Common \\
\hline$-\alpha^{3.7 /} /$ SEA & 71 & $1.45 \%$ & Common \\
\hline$\alpha \alpha^{C S / \alpha \alpha}$ & 64 & $1.31 \%$ & Common \\
\hline$\alpha \alpha^{W S} / \alpha \alpha$ & 46 & $0.94 \%$ & Common \\
\hline$-\alpha^{3.7} /-\alpha^{3.7}$ & 30 & $0.61 \%$ & Common \\
\hline$-\alpha^{4.2} /{ }_{S E A}$ & 16 & $0.33 \%$ & Common \\
\hline$\alpha \alpha^{W S} /-\alpha^{3.7}$ & 11 & $0.23 \%$ & Common \\
\hline$-\alpha^{3.7} /-\alpha^{4.2}$ & 8 & $0.16 \%$ & Common \\
\hline$\alpha \alpha^{C S /-S E A}$ & 7 & $0.14 \%$ & Common \\
\hline$H k \alpha \alpha /-S E A$ & 5 & $0.10 \%$ & Rare \\
\hline$-T H A l / \alpha \alpha$ & 5 & $0.10 \%$ & Rare \\
\hline$\alpha \alpha^{I V S-I I-55(T>G)} / \alpha \alpha$ & 5 & $0.10 \%$ & Rare \\
\hline$\alpha \alpha^{W S /-S E A}$ & 4 & $0.08 \%$ & Common \\
\hline$\alpha \alpha^{Q S / \_S E A}$ & 4 & $0.08 \%$ & Common \\
\hline$\alpha \alpha^{Q S} /-\alpha^{3.7}$ & 3 & $0.06 \%$ & Common \\
\hline$\alpha \alpha^{Q S} /-\alpha^{4.2}$ & 2 & $0.04 \%$ & Common \\
\hline$\alpha \alpha^{C S} /-\alpha^{3.7}$ & 2 & $0.04 \%$ & Common \\
\hline$-\alpha^{4.2} /-\alpha^{4.2}$ & 2 & $0.04 \%$ & Common \\
\hline$\alpha \alpha^{W S} /-\alpha^{4.2}$ & 2 & $0.04 \%$ & Common \\
\hline$H \mathrm{k} \alpha \alpha / \alpha \alpha$ & 2 & $0.04 \%$ & Rare \\
\hline$\alpha \alpha^{W S} / \alpha \alpha^{W S}$ & 1 & $0.02 \%$ & Common \\
\hline$\alpha \alpha^{C S} / \alpha \alpha^{W S}$ & 1 & $0.02 \%$ & Common \\
\hline$\alpha \alpha^{C S} /-\alpha^{4.2}$ & 1 & $0.02 \%$ & Common \\
\hline$-\alpha^{3.7} /{ }^{T H A l}$ & 1 & $0.02 \%$ & Rare \\
\hline$\alpha \alpha / \alpha \alpha \alpha^{a n t i 4.2}$ & 1 & $0.02 \%$ & Rare \\
\hline$-F l L / \alpha \alpha$ & 1 & $0.02 \%$ & Rare \\
\hline$-\alpha^{27.6} /{ }_{-S E A}$ & 1 & $0.02 \%$ & Rare \\
\hline$-\alpha^{6.9} / \_S E A$ & 1 & $0.02 \%$ & Novel \\
\hline Total & 4,884 & $100 \%$ & \\
\hline
\end{tabular}




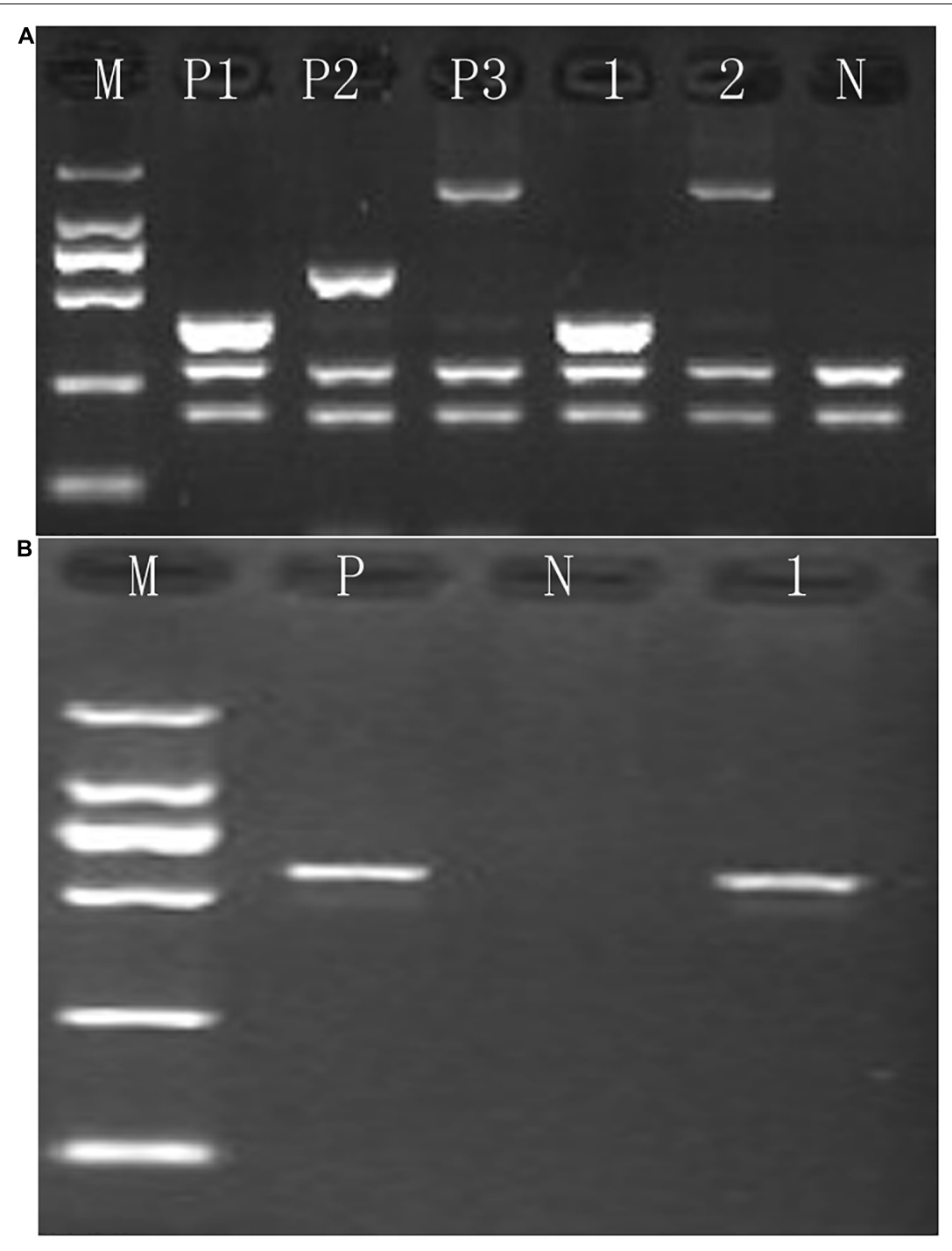

FIGURE 1 | Identification of rare $\alpha$-thalassemia using gap-PCR. (A) Electrophoresis result of _ $-{ }^{T H A l} / \alpha \alpha$ and $-\alpha^{27.6} / \alpha \alpha$ thalassemia; M, maker; P1, positive control of ${ }_{-T H A l} / \alpha \alpha ; \mathrm{P} 2$, positive control of $-\alpha^{21.9} / \alpha \alpha$; P3, positive control of $-\alpha^{27.6} / \alpha \alpha ; \mathrm{N}$, negative control; $1,{ }^{T H A l}$ thalassemia carrier; $2,-\alpha^{27.6}$ thalassemia carrier.

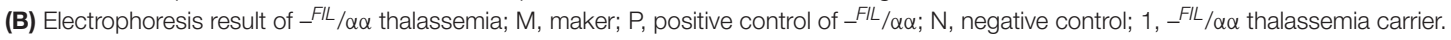

Diagnostics equipment and kit (Siemens, United States) and using the ADVIA Centaur XP Immunoassay System (Siemens, United States).

\section{Molecular Diagnosis of Thalassemia}

For each subject with positive hematological analysis results for the molecular analysis of common $\alpha$ - and $\beta$-thalassemia, we collected a further $2 \mathrm{ml}$ of peripheral blood. An automatic nucleic acid extractor (Ruibao Biological Co., Ltd., Taiwan) was used to extract the genomic DNA of the subjects. We also used Gap-PCR to detect the three common deletional $\alpha$-thalassemia mutations [Yaneng BIOscience (Shenzhen) Co. Ltd., Shenzhen]. The PCR reverse dot hybridization technique (PCR-RDB) was utilized to detect the three common non-deletional $\alpha$-thalassemia mutations and 17 common $\beta$-thalassemia mutations [Yaneng
BIOscience (Shenzhen) Co. Ltd., Shenzhen]. The $\beta$-thalassemia mutations we detected were as follows: CD41-42(-TCTT), IVS-II654(C > T), -28 (A > G), CD71/72(+ A), CD17(AAG > TAG), CD26(GAG > AAG), CD43(GAG > TAG), $-29(\mathrm{~A}>\mathrm{G})$, CD31(-C), $-32(\mathrm{C}>\mathrm{A})$, IVS-I-1 $(\mathrm{G}>\mathrm{T}), \mathrm{CD} 27 / 28(+\mathrm{C}),-$ 30( $\mathrm{T}>\mathrm{C}), \mathrm{CD} 14-15(+\mathrm{G})$, Cap + 40-43(-AAAC), initiation codon(ATG > AGG), and IVS-I-5(G>C). The experimental operations were performed strictly according to the protocols of the manufacturers.

\section{Rare Thalassemia Analysis and DNA Sequencing}

Rare $\alpha$-thalassemia genotype screening kits $\left(-{ }^{T H A I},-\alpha^{27.6}\right.$, $-\alpha^{21.9}$ ) and rare $\beta$-thalassemia genotype screening kits [Taiwanese, ${ }^{G} \gamma^{+}\left({ }^{A} \gamma \delta \beta\right)^{0}$, SEA-HPFH] were utilized for suspected 

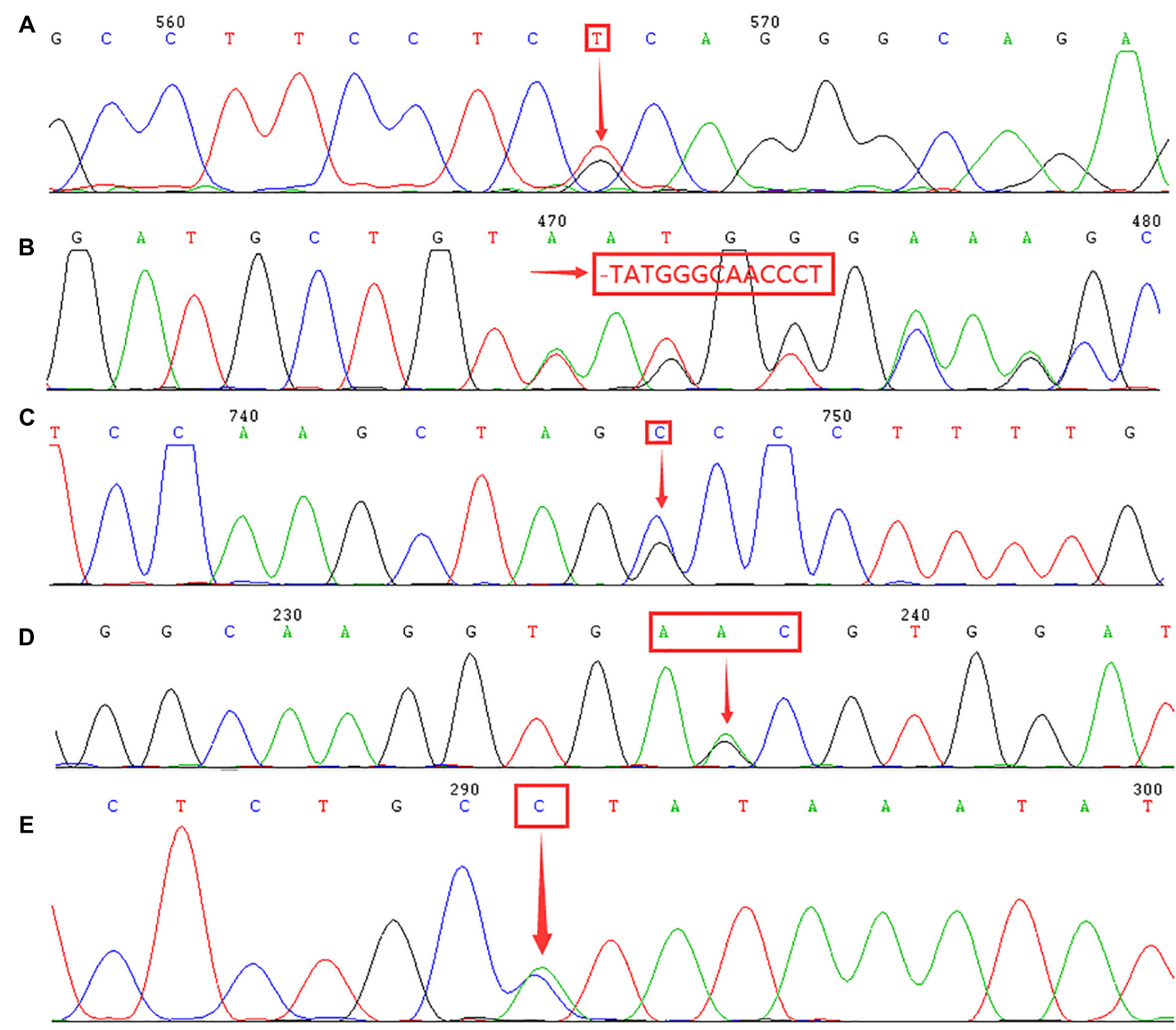

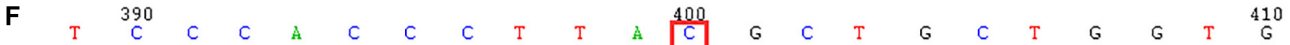
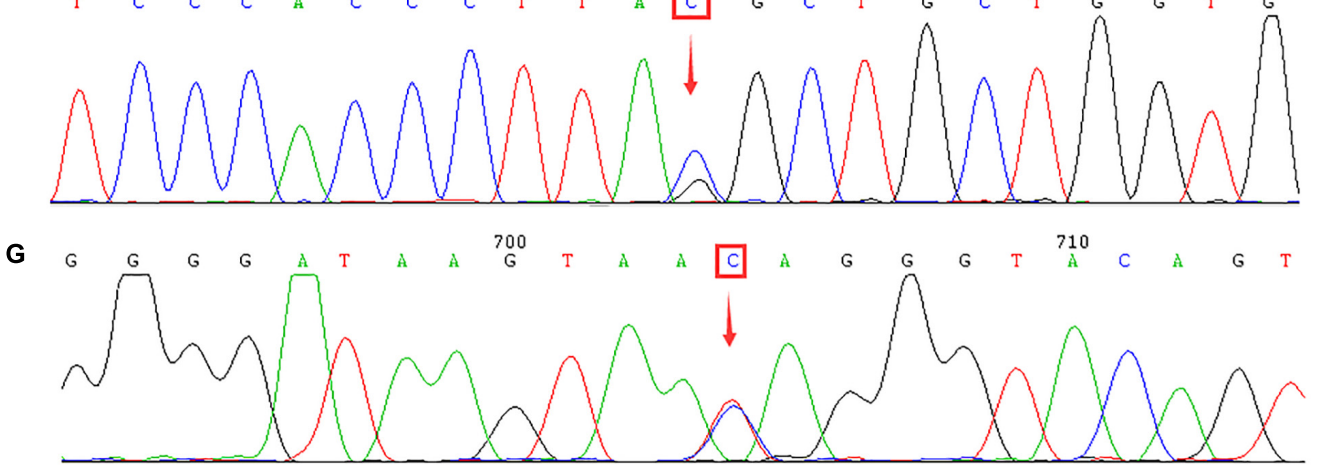

FIGURE 2 | Identification of rare $\alpha$ - and $\beta$-thalassemia mutations using DNA sequencing. Arrows indicate the location of the mutations. (A) IVS-II-55(T > G) mutation in the HBA2 gene. (B) CD54-58(-TATGGGCAACCCT) mutation in the HBB gene. (C) IVS-II-806(G > C) mutation in the HBB gene. (D) Hb Malay(AAC > AGC) mutation in the HBB gene. (E) IVS-II-672(A > C) mutation in the HBB gene. (F) IVS-I-130(G > C) mutation in the HBB gene. (G) IVS-II-81(C > T) mutation in the HBB gene.

carriers of rare $\alpha$ - or $\beta$-thalassemia deletion. Indicators included low levels of $\mathrm{Hb}$ A2 without common $\alpha$-thalassemia variants, as well as high or low levels of $\mathrm{Hb} \mathrm{A} 2$ without common $\beta$-thalassemia variants.

Gap-PCR was performed to identify the deletion of ${ }^{F I L}$. We designed specific primers according to the known DNA sequences around the breakpoints. These primer sequences were P1: TCTAAAAATTCATCCTTAAGAGAATAA and
P2: GATCTAATGTAGTAGAGATAATAACCTTTA. All primers were synthesized at Sangon Biotech (Shanghai). The amplification conditions were $96^{\circ} \mathrm{C}$ for $5 \mathrm{~min}$, then 35 cycles of $98^{\circ} \mathrm{C}$ for $30 \mathrm{~s}, 60^{\circ} \mathrm{C}$ for $1 \mathrm{~min}, 72^{\circ} \mathrm{C}$ for $2 \mathrm{~min}$, and finally $72^{\circ} \mathrm{C}$ for $10 \mathrm{~min}$. Subsequently, we performed an electrophoresis analysis.

We employed a multiplex ligation-dependent probe amplification (MLPA) assay using the SALSA MLPA Probemix 
TABLE 2 | Comparison of hematological parameters among $\alpha$-thalassemia silent carriers.

\begin{tabular}{|c|c|c|c|c|c|c|c|c|}
\hline \multirow[t]{2}{*}{ Groups } & \multicolumn{2}{|c|}{ Cases } & \multicolumn{2}{|c|}{$\operatorname{RBC}\left(\times 10^{12} / L\right)$} & \multicolumn{2}{|c|}{$\mathrm{Hb}(\mathrm{g} / \mathrm{L})$} & \multirow[t]{2}{*}{$\operatorname{MCV}(f \mathrm{l})$} & \multirow[t]{2}{*}{ MCH (pg) } \\
\hline & $\mathbf{M}$ & $\mathbf{F}$ & $\mathbf{M}$ & $\mathbf{F}$ & $\mathbf{M}$ & $\mathbf{F}$ & & \\
\hline$\alpha \alpha^{Q S} / \alpha \alpha$ & 23 & 27 & $5.51 \pm 0.48$ & $4.65 \pm 0.39$ & $138.5 \pm 10.0$ & $108.5 \pm 5.8$ & $75.20 \pm 3.44$ & $23.96 \pm 1.43$ \\
\hline$\alpha \alpha^{C S} / \alpha \alpha$ & 9 & 21 & $5.62 \pm 0.08$ & $4.44 \pm 0.37$ & $147.2 \pm 5.6$ & $117.7 \pm 7.4$ & $80.77 \pm 4.08$ & $26.34 \pm 1.02$ \\
\hline$\alpha \alpha^{W S} / \alpha \alpha$ & 6 & 8 & $5.67 \pm 0.16$ & $4.32 \pm 0.28$ & $151.3 \pm 3.1$ & $126.6 \pm 5.2$ & $82.21 \pm 4.13$ & $27.57 \pm 1.80$ \\
\hline$\alpha \alpha^{I V S-1 I-55(T>G)} / \alpha \alpha$ & 2 & 2 & $5.23 \pm 0.40$ & $4.25 \pm 0.12$ & $150.5 \pm 6.4$ & $126.0 \pm 7.1$ & $84.00 \pm 2.71$ & $29.28 \pm 0.93$ \\
\hline$-\alpha^{4.2} / \alpha \alpha$ & 17 & 51 & $5.65 \pm 0.28$ & $4.53 \pm 0.35$ & $148.9 \pm 6.4$ & $119.3 \pm 7.8$ & $80.79 \pm 3.81$ & $26.56 \pm 1.02$ \\
\hline$-\alpha^{3.7} / \alpha \alpha$ & 42 & 160 & $5.63 \pm 0.35$ & $4.56 \pm 0.36$ & $152.6 \pm 7.6$ & $119.9 \pm 7.7$ & $80.45 \pm 3.06$ & $26.53 \pm 1.11$ \\
\hline $\mathrm{F}$ & & & 0.899 & 1.722 & 10.130 & 13.185 & 24.014 & 50.875 \\
\hline$P$ & & & 0.485 & 0.130 & $<0.001$ & $<0.001$ & $<0.001$ & $<0.001$ \\
\hline
\end{tabular}

M, male; F, female; $\mathrm{Hb}$, hemoglobin; $\mathrm{MCH}$, mean corpuscular hemoglobin; $\mathrm{MCV}$, mean corpuscular volume; $\mathrm{RBC}$, red blood cell.

P140-C1HBA (MRC-Holland, Amsterdam, Netherlands) to detect the known or unknown globin gene deletions. DNA sequencing was performed when we observed suspected carriers of rare thalassemia mutations.

\section{Statistical Analysis}

The statistical analysis was conducted using SPSS19.0 software. The measurement data were expressed as $\bar{X} \pm s$, and we utilized the independent sample $t$-test to compare the means of the two groups. We also applied the chi-square test to compare the detection rates between the groups. A value of $p<0.05$ was considered statistically significant.

\section{RESULTS}

Of the 17,407 suspected cases, 4,884 subjects were diagnosed with $\alpha$-thalassemia, including 31 genotypes. Of these, the $S E A / \alpha \alpha(70.17 \%)$ mutation was the most common deletional mutation, followed by $-\alpha^{3.7} / \alpha \alpha(18.37 \%)$ and $-\alpha^{4.2} / \alpha \alpha$ (3.34\%). The three most common non-deletional mutations were $\alpha \alpha^{Q S} / \alpha \alpha, \alpha \alpha^{C S} / \alpha \alpha$, and $\alpha \alpha^{W S} / \alpha \alpha$, with frequencies of $2.05 \%$, $1.31 \%$, and $0.94 \%$, respectively. Besides, nine genotypes of rare $\alpha$-thalassemia were detected, of which ${ }^{T H A I} / \alpha \alpha, \mathrm{Hk} \alpha \alpha /{ } S E A$, and $\alpha \alpha^{I V S-I I-55(T>G)} / \alpha \alpha$ were the most common. Of these nine genotypes, our study was the first to detect a $-F I L / \alpha \alpha$ case in Fujian province, while $-\alpha^{27.6} /{ }^{S E A}$ and $\alpha \alpha^{I V S-I I-55(T>G)} / \alpha \alpha$ had never before been identified in Quanzhou prefecture (Table 1 and Figures 1, 2).

To further analyze the hematological phenotype $\alpha \alpha^{I V S-I I-55(T>G)} / \alpha \alpha$, we performed a comparison of the hematological parameters among the different genotypes of silent $\alpha$-thalassemia. As Table 2 illustrates, there are significant differences among the silent $\alpha$-thalassemia groups in the hematological parameters of $\mathrm{Hb}, \mathrm{MCV}$, and $\mathrm{MCH}$. Among them, $\alpha \alpha^{Q S} / \alpha \alpha$-positive cases exhibited lower levels of $\mathrm{Hb}, \mathrm{MCV}$, and $\mathrm{MCH}$ than those of other groups, and the hematological phenotype was similar to that of $\alpha$-thalassemia minor. Conversely, the rare genotype $\alpha \alpha^{I V S-I I-55(T>G)} / \alpha \alpha$ displayed a milder hematological phenotype similar to $\alpha \alpha^{W S} / \alpha \alpha$.

Additionally, 2,056 cases were diagnosed with $\beta$-thalassemia. Of these, there were 2,035 cases with $\beta$-thalassemia minor and 21 cases with $\beta$-thalassemia intermedia or major. The most common $\beta$-thalassemia variants were $\beta^{I V S-I I-654} / \beta^{N}$ (36.19\%) and $\beta^{C D 41-42} / \beta^{N}(29.82 \%)$, followed by $\beta^{C D 17} / \beta^{N}$ (16.78\%), $\beta^{C D 26} / \beta^{N}$ (5.35\%), and $\beta^{-28} / \beta^{N}$ (4.57\%). These five common mutations accounted for $92.71 \%$ of $\beta$-thalassemia gene mutations. In this study, 17 cases of rare $\beta$-thalassemia variants were identified, of which $\beta^{C D 54-58} / \beta^{N}$ and $\beta^{I V S-I I-806} / \beta^{N}$ mutations were the first to be reported in Quanzhou, while $\beta^{\text {Malay }} / \beta^{N}$ and $\beta^{I V S-I I-672} / \beta^{N}$ had not previously been identified in Fujian province. Moreover, one subject carried two rare $\beta$-thalassemia mutations $\left(\beta^{I V S-I-130} / \beta^{I V S-I I-81}\right)$, which has never been encountered before (Table 3 and Figure 2).

Among the suspected cases, 145 were diagnosed with compound $\alpha$ and $\beta$-thalassemia, while 34 of these subjects possessed the two most prevalent genotype mutations, $S E A / \alpha \alpha / \beta^{I V S-I I-654} / \beta^{N}$ and $-\alpha^{3.7} / \alpha \alpha / \beta^{C D 41-42} / \beta^{N}$ (Table 4).

Moreover, 11 subjects with low levels of $\mathrm{Hb}$ A2 or $\beta$-thalassemia carrier with normal levels of $\mathrm{Hb}$ A2 were suspected of having the $\delta$-globin gene mutation. We confirmed that none of these subjects were suffering from iron deficiency anemia. Subsequently, we performed DNA sequencing to detect the $\mathrm{HBD}$ gene and discovered two $\delta$-globin gene mutations. Two cases of known mutations [$77(\mathrm{~T}>\mathrm{C})]$ and one case of the novel $\delta$-globin gene mutation $[\mathrm{CD} 44(\mathrm{TCC}>$ TGC) (HBD:c.134C > G)] were identified (Figure 3).

In this study, 39 types of mutations were identified in the allele frequencies of $\alpha(\beta)$ thalassemia mutation chromosomes, including $13 \alpha$-thalassemia gene mutations and $26 \beta$-thalassemia mutations. Of the $\alpha$-thalassemia mutant chromosomes, 5,205 chromosomes carried $\alpha$-thalassemia gene mutations, of which the most frequent mutation was _SEA (69.01\%), followed by $-\alpha^{3.7}(21.34),-\alpha^{4.2}(3.96 \%), \alpha \alpha^{Q S}(2.19 \%), \alpha \alpha^{C S}(1.59 \%)$, and $\alpha \alpha^{W S}(1.48 \%)$ (Table 5). Regarding the $\beta$-thalassemia mutant chromosomes, 2,223 chromosomes carrying $\beta$-thalassemia gene mutations were detected, of which the five most common mutations were IVS-II-654(C > T), CD41-42(-TCTT), $\mathrm{CD} 17(\mathrm{~A}>\mathrm{T}), \mathrm{CD} 26(\mathrm{G}>\mathrm{A})$, and $-28(\mathrm{~A}>\mathrm{G})$. The allele frequencies were $36.08 \%, 29.55 \%, 17.23 \%, 5.80 \%$, and $4.77 \%$, respectively (Table 6).

To further investigate the hemoglobin variants, we performed a DNA sequencing analysis. Altogether, we detected 24 cases 
TABLE 3 | Distribution of $\beta$-thalassemia genotypes in Quanzhou Prefecture.

\begin{tabular}{|c|c|c|c|c|}
\hline Types & Genotypes & Cases & Frequency & Class \\
\hline \multirow[t]{24}{*}{$\beta^{0} / \beta^{N}$ or $\beta^{+} / \beta^{N}$} & $\beta^{I V S-1 I-654} / \beta^{N}$ & 744 & $36.19 \%$ & Common \\
\hline & $\beta^{C D 41-42 / \beta^{N}}$ & 613 & $29.82 \%$ & Common \\
\hline & $\beta^{C D 17} / \beta^{N}$ & 345 & $16.78 \%$ & Common \\
\hline & $\beta^{C D 26} / \beta^{N}$ & 110 & $5.35 \%$ & Common \\
\hline & $\beta^{-28} / \beta^{N}$ & 94 & $4.57 \%$ & Common \\
\hline & $\beta^{C D 27 / 28} / \beta^{N}$ & 47 & $2.29 \%$ & Common \\
\hline & $\beta^{C D 71-72 / \beta^{N}}$ & 22 & $1.07 \%$ & Common \\
\hline & $\beta^{C D 43} / \beta^{N}$ & 18 & $0.88 \%$ & Common \\
\hline & $\beta^{-29} / \beta^{N}$ & 8 & $0.39 \%$ & Common \\
\hline & $\beta^{C A P+40-43} \beta^{N}$ & 7 & $0.34 \%$ & Common \\
\hline & $\beta^{I n t} / \beta^{N}$ & 4 & $0.19 \%$ & Common \\
\hline & $\beta^{S E A-H P F H} / \beta^{N}$ & 3 & $0.15 \%$ & Rare \\
\hline & $\beta^{I V S-I-1} / \beta^{N}$ & 3 & $0.15 \%$ & Common \\
\hline & $\beta^{\text {Term } C D+32} / \beta^{N}$ & 3 & $0.15 \%$ & Rare \\
\hline & $\beta^{C D 53} / \beta^{N}$ & 2 & $0.10 \%$ & Rare \\
\hline & $\beta^{C D 37} / \beta^{N}$ & 2 & $0.10 \%$ & Rare \\
\hline & $\beta^{I V S-I-5} / \beta^{N}$ & 2 & $0.10 \%$ & Common \\
\hline & $\beta^{C D 14-15} / \beta^{N}$ & 2 & $0.10 \%$ & Common \\
\hline & $\beta^{-90} / \beta^{N}$ & 1 & $0.05 \%$ & Rare \\
\hline & $\beta^{C D 54-58} / \beta^{N}$ & 1 & $0.05 \%$ & Rare \\
\hline & $\beta^{\text {Malay } / \beta^{N}}$ & 1 & $0.05 \%$ & Rare \\
\hline & $\beta^{C D 3} / \beta^{N}$ & 1 & $0.05 \%$ & Rare \\
\hline & $\beta^{I V S-1 I-806} / \beta^{N}$ & 1 & $0.05 \%$ & Rare \\
\hline & $\beta^{I V S-I I-672} / \beta^{N}$ & 1 & $0.05 \%$ & Rare \\
\hline \multirow[t]{14}{*}{$\beta^{+} / \beta^{+}$or $\beta^{0} / \beta^{+}$or $\beta^{0} / \beta^{0}$} & $\beta^{I V S-I I-654} / \beta^{I V S-I I-654}$ & 4 & $0.19 \%$ & Common \\
\hline & $\beta^{I V S-I I-654} / \beta^{C D 17}$ & 4 & $0.19 \%$ & Common \\
\hline & $\beta^{C D 41-42 / \beta^{C D 41-42}}$ & 2 & $0.10 \%$ & Common \\
\hline & $\beta^{C D 26} / \beta^{C D 26}$ & 2 & $0.10 \%$ & Common \\
\hline & $\beta^{C D 17} / \beta^{C D 17}$ & 1 & $0.05 \%$ & Common \\
\hline & $\beta^{I V S-I I-654 M} / \beta^{-28}$ & 1 & $0.05 \%$ & Common \\
\hline & $\beta^{I V S-1 I-654} / \beta^{C D 27 / 28}$ & 1 & $0.05 \%$ & Common \\
\hline & $\beta^{I V S-I I-654} / \beta^{C D 41-42}$ & 1 & $0.05 \%$ & Common \\
\hline & $\beta^{C D 41-42 / \beta^{C D 17}}$ & 1 & $0.05 \%$ & Common \\
\hline & $\beta^{C D 41-42 / \beta^{C D 26}}$ & 1 & $0.05 \%$ & Common \\
\hline & $\beta^{I V S-I I-654 M} / \beta^{C D 26}$ & 1 & $0.05 \%$ & Common \\
\hline & $\beta^{C D 41-42 / \beta^{C D 43}}$ & 1 & $0.05 \%$ & Common \\
\hline & $\beta^{I V S-I-130} / \beta^{I V S-I I-81}$ & 1 & $0.05 \%$ & Rare \\
\hline & Total & 2056 & $100 \%$ & \\
\hline
\end{tabular}

of $\mathrm{Hb}$ Q-Thailand [CD74(GAC > CAC)], two cases of $\mathrm{Hb}$ G-Honolulu [CD30(GAG > CAG)], and one case of $\mathrm{Hb}$ Owari [CD121(GTG > ATG)], all of which were induced by the $\alpha$-globin gene mutation. Similarly, we identified 37 cases of $\mathrm{Hb} \mathrm{New}$ York [CD113(GTG > GAG)], 12 cases of $\mathrm{Hb}$ J-Bangkok [CD56(GGC > GAC)], one case of Hb Miyashiro [CD23(GTT > GGT)], and one case of Hb G-Coushatta $[\mathrm{CD} 22(\mathrm{GAA}>\mathrm{GCA})]$. These cases were caused by the $\beta$-globin gene mutation (Figure 4).

By analyzing the spectrum of thalassemia genotypes in Fujian and the neighboring provinces, we discovered that the highest frequency genotypes of deletional $\alpha$-thalassemia were similar. However, the mutations in $\alpha$-thalassemia and $\beta$-thalassemia showed distinct regional differences. As Table 7 reveals, $\alpha \alpha^{Q S}$ was
TABLE 4 | Distribution of compound $\alpha$ and $\beta$-thalassemia in Quanzhou Prefecture.

\begin{tabular}{lcccccccc}
\hline Genotypes & SEA / & $-\alpha^{3.7 /}$ & $-\alpha^{4.2} /$ & $\alpha \alpha^{W S /}$ & $\alpha \alpha^{C S /}$ & $\alpha \alpha^{Q S /}$ & $\begin{array}{c}-\alpha^{3.7 /-}-\alpha^{3.7 /-} \\
\text { SEA }\end{array}$ & $\alpha^{3.7}$ \\
& $\alpha \alpha$ & $\alpha \alpha$ & $\alpha \alpha$ & $\alpha \alpha$ & $\alpha \alpha$ & $\alpha \alpha$ & & \\
\hline$\beta^{I V S-I I-654 / \beta^{N}}$ & 21 & 10 & 3 & 3 & 2 & 2 & 0 & 1 \\
$\beta^{C D 41-42 / \beta^{N}}$ & 13 & 14 & 4 & 4 & 0 & 1 & 0 & 0 \\
$\beta^{C D 17} / \beta^{N}$ & 10 & 13 & 1 & 2 & 3 & 2 & 0 & 0 \\
$\beta^{C D 26 / \beta^{N}}$ & 3 & 5 & 0 & 2 & 0 & 0 & 1 & 0 \\
$\beta^{-28 / \beta^{N}}$ & 3 & 6 & 1 & 0 & 1 & 0 & 0 & 0 \\
$\beta^{C D 27 / 28 / \beta^{N}}$ & 0 & 2 & 0 & 0 & 0 & 0 & 0 & 0 \\
$\beta^{C D 71-72 / \beta^{N}}$ & 0 & 3 & 0 & 0 & 1 & 0 & 0 & 0 \\
$\beta^{C A P+40-43} \beta^{N}$ & 4 & 0 & 1 & 0 & 0 & 0 & 1 & 0 \\
$\beta^{\text {Int } / \beta^{N}}$ & 0 & 1 & 0 & 0 & 0 & 0 & 0 & 0 \\
$\beta^{C D 26 / \beta^{C D 26}}$ & 0 & 0 & 0 & 0 & 1 & 0 & 0 & 0
\end{tabular}

the most common non-deletional $\alpha$-thalassemia variant in Fujian and Jiangxi province, Guangdong and Hunan province mainly exhibited the $\alpha \alpha^{C S}$ mutation, and $\alpha \alpha^{W S}$ was the most widespread non-deletional $\alpha$-thalassemia variant in Guangxi province. The IVS-II-654(C $>$ T) and CD41-42(-TCTT) mutations were the most common $\beta$-thalassemia mutations in Fujian and its neighboring provinces, except in Guangxi province, which mainly carried CD41-42(-TCTT) and CD17(A > T) mutations.

\section{DISCUSSION}

In China, there is a high prevalence of thalassemia in the regions south of the Yangtze River, particularly in Guangdong and Guangxi. In 2019, a study showed that the prevalence of thalassemia in Fujian was 6.8\% (Huang et al., 2019). Few studies are available on the genotypes of thalassemia in Quanzhou prefecture, and there have been few investigations into rare thalassemia and hemoglobinopathy. In this study, we present the spectrum mutation of rare thalassemia and hemoglobinopathy in Quanzhou, Southeast China.

We discovered 7,085 subjects who harbored thalassemia mutations; therefore, the detection rate was $40.70 \%$. As Table 5 displays, we identified 5,205 chromosomes carrying $\alpha$-thalassemia gene mutations. The three most common deletional variants were $-S E A,-\alpha^{3.7}$, and $-\alpha^{4.2}$, which is consistent with previous studies in Fujian province and neighboring provinces (Xu et al., 2004; Zheng et al., 2011; Lin et al., 2014, 2019; Dai et al., 2017; Cao et al., 2019; Liu et al., 2019; Chen M. F. et al., 2020). However, the non-deletional variants of $\alpha$-thalassemia showed a great disparity with other regions (Xu et al., 2004; Zheng et al., 2011; Lin et al., 2014; Liu et al., 2019). Among these variants, 22 cases of rare $\alpha$-thalassemia were detected, with ${ }_{-}^{T H A I} / \alpha \alpha$ and $H k \alpha \alpha /-S E A$ being the most common. This is consistent with another study conducted in Fujian province (Huang et al., 2019). Before this study, $F I L / \alpha \alpha$ had only ever been detected in Taiwan; thus, this was the first-ever reported case in Fujian province (Chen et al., 2002). The ${ }^{F I L}$ deletion covers both the $\alpha 1$ and $\alpha 2$ gene, which leads to $\alpha$-thalassemia major if compounded with - $S E A$ deletion. We identified five cases of the $\alpha \alpha^{I V S-I I-55(T>G)} / \alpha \alpha$ 

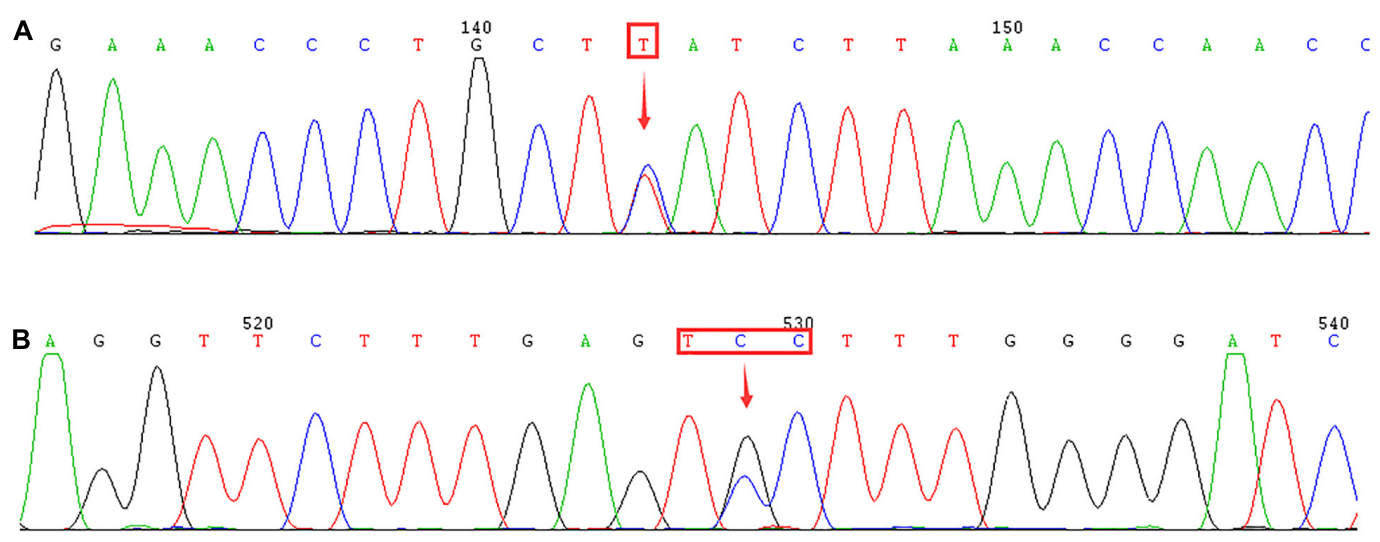

FIGURE 3 | Identification of $\delta$-globin gene mutation using DNA sequencing. Arrows indicate the location of the mutations. (A) $-77(\mathrm{~T}>\mathrm{C})(\mathrm{HBD}: \mathrm{C}$.- $127 \mathrm{~T}>\mathrm{C})$ mutation in the HBD gene. (B) Novel mutation of CD44(TCC > TGC) (HBD:c.134C > G) in the HBD gene.

TABLE 5 | Allele frequency of $\alpha$-thalassemia mutations in Quanzhou Prefecture.

\begin{tabular}{|c|c|c|c|}
\hline \multirow{2}{*}{$\begin{array}{l}\text { Mutation type } \\
\text { SEA }\end{array}$} & \multirow{2}{*}{$\begin{array}{l}\text { HGVS name } \\
\text { NC_000016.9:g.215400_234700del }\end{array}$} & \multicolumn{2}{|c|}{ Allele Frequency } \\
\hline & & 3592 & $69.01 \%$ \\
\hline$-\alpha^{3.7}$ & NC_000016.9:g.223300_227103del & 1111 & $21.34 \%$ \\
\hline$-\alpha^{4.2}$ & NC_000016.9:g.219817_(223755_224074)del & 206 & $3.96 \%$ \\
\hline$\alpha \alpha^{Q S}$ & HBA2: c.377T > C & 114 & $2.19 \%$ \\
\hline$\alpha \alpha^{C S}$ & HBA2: c.427T > C & 83 & $1.59 \%$ \\
\hline$\alpha \alpha^{W S}$ & HBA2: c.369C > G & 77 & $1.48 \%$ \\
\hline$H k \alpha \alpha$ & 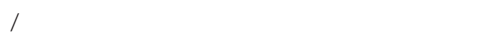 & 7 & $0.13 \%$ \\
\hline$-T H A l$ & NC_000016.9:g.199800_233300del & 6 & $0.12 \%$ \\
\hline$\alpha \alpha^{I V S-\| l-55(T>G)}$ & HBA2: $\mathrm{c} .300+55 \mathrm{~T}>\mathrm{G}$ & 5 & $0.10 \%$ \\
\hline$\alpha \alpha \alpha^{\text {anti4.2 }}$ & / & 1 & $0.02 \%$ \\
\hline fFlL & NC_000016.9:g.200820_232670del & 1 & $0.02 \%$ \\
\hline$-\alpha^{27.6}$ & NC_000016.9:g.198215_225854del & 1 & $0.02 \%$ \\
\hline$-\alpha^{6.9}$ & NG_000006.1:g.29785_36746del & 1 & $0.02 \%$ \\
\hline Total & & 5205 & $100 \%$ \\
\hline
\end{tabular}

HGVS, human genome variation society.

mutation in this study, a mutation that was first identified in Fuzhou city and subsequently reported in the Nanping region of Fujian province (Cao et al., 2019; Chen M. F. et al., 2020). This indicates that $\alpha \alpha^{I V S-I I-55(T>G)}$ may be an increasingly common mutation that will possibly become more prevalent in Fujian province. Further analysis of the hematological phenotype of $\alpha \alpha^{I V S-I I-55(T>G)} / \alpha \alpha$ provided similar results as tests for $\alpha \alpha^{W S} / \alpha \alpha$.

In this study, we detected 2,223 chromosomes carrying $\beta$-thalassemia gene mutations. The most frequent mutation was IVS-II-654 $(\mathrm{C}>\mathrm{T})$, which was consistent with several regions in South China (Lin et al., 2014; Dai et al., 2017; Cao et al., 2019; Liu et al., 2019; Chen M. F. et al., 2020). However, the most prevalent $\beta$-thalassemia mutation in the nearby provinces of Guangdong and Guangxi is CD41-42(-TCTT) (Xu et al., 2004; Zheng et al., 2011). Our study indicates a higher frequency of the $\mathrm{CD} 26(\mathrm{G}>\mathrm{A})$ mutation in comparison with other regions in Fujian province. A previous study demonstrated that $\mathrm{CD} 26(\mathrm{G}>\mathrm{A})$ is the most common $\beta$-thalassemia mutation
TABLE 6 | Allele frequency of $\beta$-thalassemia mutations in Quanzhou Prefecture.

\begin{tabular}{|c|c|c|c|}
\hline Mutation type & HGVS name & Allele & Frequency \\
\hline IVS-II-654(C > T) & HBB: c.316-197C > T & 802 & $36.08 \%$ \\
\hline CD41-42(-TCTT) & HBB: c.126_129delCTाT & 657 & $29.55 \%$ \\
\hline $\operatorname{CD17}(\mathrm{A}>\mathrm{T})$ & HBB: c.52A > T & 383 & $17.23 \%$ \\
\hline $\mathrm{CD} 26(\mathrm{G}>\mathrm{A})$ & HBB: c.79G > A & 129 & $5.80 \%$ \\
\hline$-28(A>G)$ & HBB: c. $-78 \mathrm{~A}>\mathrm{G}$ & 106 & $4.77 \%$ \\
\hline CD27/28(+ C) & HBB: c.84_85insC & 50 & $2.25 \%$ \\
\hline CD71-72 (+ A) & HBB: c.216_217insA & 26 & $1.17 \%$ \\
\hline $\operatorname{CD43}(G>T)$ & HBB: c. $130 G>T$ & 19 & $0.85 \%$ \\
\hline CAP + 40-43(-AAAC) & HBB: c.-11_-8delAAAC & 13 & $0.58 \%$ \\
\hline$-29(A>G)$ & HBB: c.-79A > G & 8 & $0.36 \%$ \\
\hline Initiation codon( $(T$ > G) & HBB: c.2T > G & 5 & $0.22 \%$ \\
\hline \multirow[t]{2}{*}{ SEA-HPFH } & NC_000011.10:g.5222877_525 & 3 & $0.13 \%$ \\
\hline & 0288del & & \\
\hline Term CD + 32(A > C) & HBB: $\mathrm{c} .+32 \mathrm{~A}>\mathrm{C}$ & 3 & $0.13 \%$ \\
\hline CD53(-T) & HBB: c.162delT & 3 & $0.13 \%$ \\
\hline $\operatorname{CD} 37(G>A)$ & HBB: c.113G > A & 2 & $0.09 \%$ \\
\hline IVS-I-1(G > T) & HBB: c.92 + 1G > T & 2 & $0.09 \%$ \\
\hline CD14-15(+ G) & HBB: c.45_46insG & 2 & $0.09 \%$ \\
\hline IVS-I-5(G > C) & HBB: c. $92+5 G>C$ & 2 & $0.09 \%$ \\
\hline$-90(C>T)$ & HBB: c. $-140 \mathrm{C}>\mathrm{T}$ & 1 & $0.04 \%$ \\
\hline $\mathrm{CD} 3(\mathrm{C}>\mathrm{T})$ & HBB: $c .10 \mathrm{C}>\mathrm{T}$ & 1 & $0.04 \%$ \\
\hline CD54-58(-TATGGG & HBB: c.165_177 delT & 1 & $0.04 \%$ \\
\hline CAACCCT) & ATGGGCAACCCT & & \\
\hline IVS-II-806(G > C) & HBB: c.316-45G > C & 1 & $0.04 \%$ \\
\hline IVS-I-130(G > C) & HBB: c.93-1G > C & 1 & $0.04 \%$ \\
\hline IVS-II-81(C > T) & HBB: $\mathrm{c} .315+81 \mathrm{C}>\mathrm{T}$ & 1 & $0.04 \%$ \\
\hline Hb Malay(A > G) & HBB: c.59A > G & 1 & $0.04 \%$ \\
\hline IVS-II-672 (A > C) & HBB: c.316-179 A > C & 1 & $0.04 \%$ \\
\hline Total & & 2,223 & $100 \%$ \\
\hline
\end{tabular}

HGVS, human genome variation society.

in Yunnan province, which is located in Southwestern China (Zhang et al., 2012). In this research, we detected a diverse range of rare or novel $\beta$-thalassemia variants. Among them, this was only the second time the $\beta^{I V S-I I-806} / \beta^{N}$ mutation, 


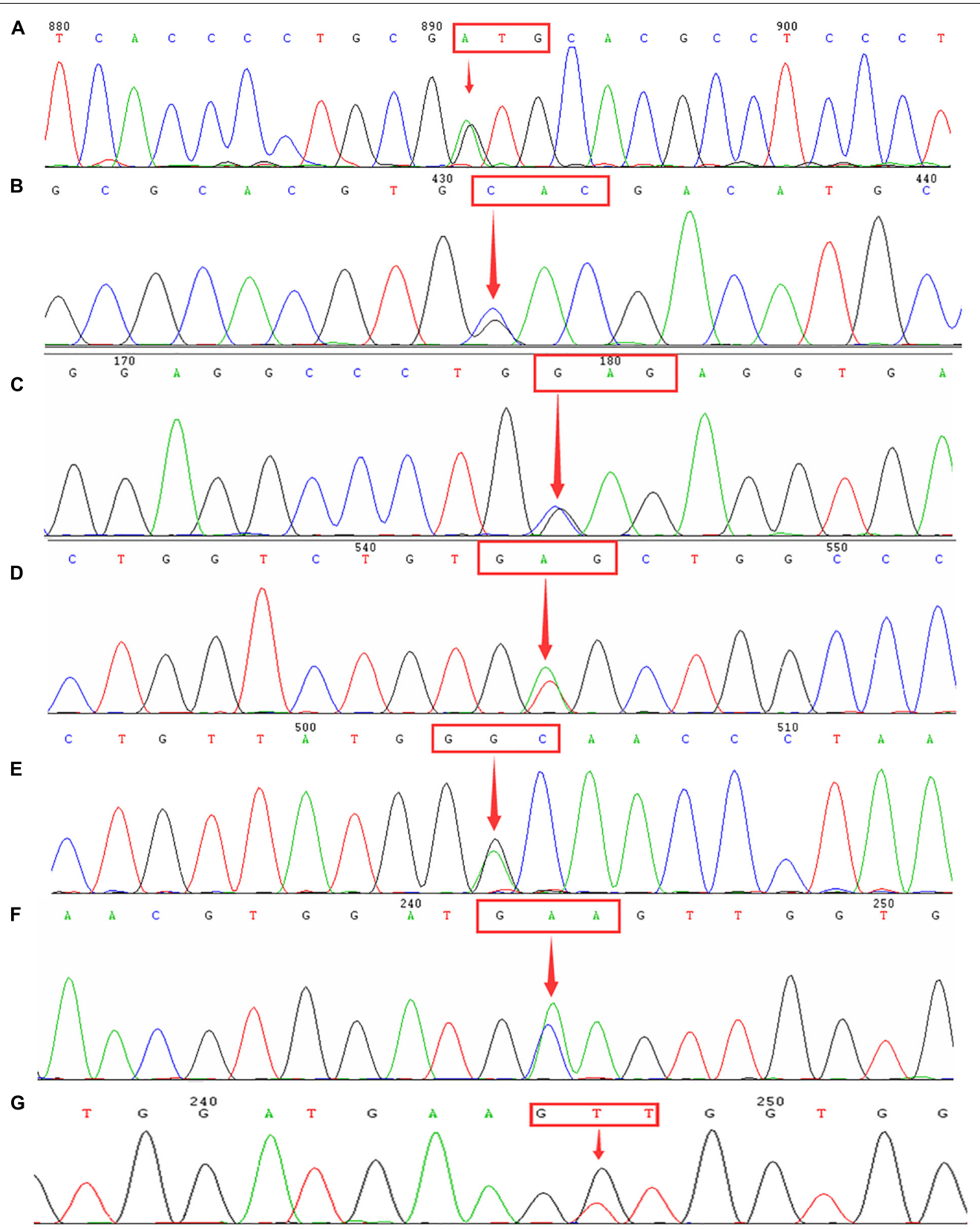

FIGURE 4 | Identification of hemoglobinopathies using DNA sequencing. Arrows indicate the location of the mutations. (A) $\mathrm{Hb}$ Owari (GTG > ATG at codon 121) mutation in the HBA1 gene. (B) Hb Q-Thailand (GAC > CAC at codon 74) mutation in the HBA1 gene. (C) Hb G-Honolulu (GAG > CAG at codon 30) mutation in the HBA2 gene. (D) Hb New York (GTG > GAG at codon 113) mutation in the HBB gene. (E) Hb J-Bangkok (GGC > GAC at codon 56) mutation in the HBB gene. (F) Hb G-Coushatta (GAA > GCA at codon 22) in the HBB gene. (G) Hb Miyashiro (GTT > GGT at codon 23) mutation in the HBB gene.

which was first identified in the Nanping region north of Fujian, had been identified in humans (Chen M. F. et al., 2020). Additionally, we made the earliest discovery of the rare mutations of $\mathrm{Hb}$ Malay(AAC > AGC), IVS-II-672(A > C), and IVS-I$130(\mathrm{G}>\mathrm{C})$ in Fujian province. In the Chinese population, $\mathrm{Hb}$ Malay is an extremely rare "Hb Knossos-like" $\beta^{+}$-thalassemia abnormality, with only one known recorded case (Ma et al., 2000). This mutation is thought to create an alternate splicing site between codons 17 and 18, reducing the efficiency of the normal donor splice site at IVS-I to about 60\% (Yang et al., 1989). The IVS-II-672(A > C) mutation had only been previously reported in Guangxi province, which suggests that it is a silent mutation, as the red blood cell indices are normal and there are normal or borderline $\mathrm{Hb}$ A2 levels (Zhao et al., 2016). However, in the case of our study, low levels of hemoglobin $\left(106 \times 10^{12} \mathrm{~g} / \mathrm{L}\right)$ and higher levels of $\mathrm{Hb} \mathrm{A} 2$ (4.5\%) were observed. Thus, more research should be conducted to reveal whether the IVS-II-672 $(\mathrm{A}>\mathrm{C})$ mutation causes $\beta^{+}$-thalassemia. 
TABLE 7 | Comparison of allele frequency of thalassemia mutations in Fujian and neighboring provinces.

\begin{tabular}{|c|c|c|c|c|c|c|c|c|}
\hline \multirow[t]{2}{*}{ Genotypes } & \multicolumn{4}{|c|}{ Fujian Province } & \multirow{2}{*}{$\begin{array}{c}\text { Guangdong } \\
\text { Province (Xu } \\
\text { et al., 2004) }\end{array}$} & \multirow{2}{*}{$\begin{array}{l}\text { Guangxi Province } \\
\text { (Zheng et al., 2011) }\end{array}$} & \multirow{2}{*}{$\begin{array}{l}\text { Jiangxi Province } \\
\text { (Lin et al., 2014) }\end{array}$} & \multirow{2}{*}{$\begin{array}{l}\text { Hunan Province } \\
\text { (Liu et al., 2019) }\end{array}$} \\
\hline & $\begin{array}{l}\text { Quanzhou } \\
\text { (this study) }\end{array}$ & $\begin{array}{l}\text { Fuzhou (Cao } \\
\text { et al., 2019) }\end{array}$ & $\begin{array}{l}\text { Longyan (Dai } \\
\text { et al., 2017) }\end{array}$ & $\begin{array}{l}\text { Nanping (Chen } \\
\text { M. F. et al., } \\
\text { 2020) }\end{array}$ & & & & \\
\hline \multicolumn{9}{|l|}{$\alpha$-thalassemia } \\
\hline _SEA & $69.01 \%$ & $77.58 \%$ & $81.76 \%$ & $72.68 \%$ & $48.54 \%$ & $68.50 \%$ & $66.51 \%$ & $52.88 \%$ \\
\hline$-\alpha^{3.7}$ & $21.34 \%$ & $14.50 \%$ & $13.27 \%$ & $15.30 \%$ & $36.40 \%$ & $16.36 \%$ & $22.86 \%$ & $31.73 \%$ \\
\hline$-\alpha^{4.2}$ & $3.96 \%$ & $3.29 \%$ & $4.97 \%$ & $4.10 \%$ & $11.09 \%$ & $8.40 \%$ & $8.08 \%$ & $9.11 \%$ \\
\hline$\alpha \alpha^{Q S}$ & $2.19 \%$ & $2.69 \%$ & - & $2.46 \%$ & $0.42 \%$ & $0.62 \%$ & $1.62 \%$ & $1.15 \%$ \\
\hline$\alpha \alpha^{C S}$ & $1.59 \%$ & $0.45 \%$ & - & $0.82 \%$ & $2.09 \%$ & $3.03 \%$ & $0.92 \%$ & $3.25 \%$ \\
\hline$\alpha \alpha^{W S}$ & $1.48 \%$ & $1.05 \%$ & - & $0.55 \%$ & - & $3.09 \%$ & - & $1.88 \%$ \\
\hline \multicolumn{9}{|l|}{$\beta$-thalassemia } \\
\hline IVS-II-654(C > T) & $36.08 \%$ & $41.81 \%$ & $44.95 \%$ & $35.27 \%$ & $24.75 \%$ & $5.26 \%$ & $40.70 \%$ & $38.89 \%$ \\
\hline CD41-42(-TCTT) & $29.55 \%$ & $36.10 \%$ & $28.11 \%$ & $25.12 \%$ & $36.36 \%$ & $48.37 \%$ & $30.81 \%$ & $27.49 \%$ \\
\hline $\operatorname{CD17}(\mathrm{A}>\mathrm{T})$ & $17.23 \%$ & $9.74 \%$ & $9.08 \%$ & $10.14 \%$ & $4.04 \%$ & $27.40 \%$ & $5.23 \%$ & $13.82 \%$ \\
\hline CD26(G > A) & $5.80 \%$ & $1.90 \%$ & $1.46 \%$ & $4.35 \%$ & $5.05 \%$ & $4.51 \%$ & $0.58 \%$ & $3.13 \%$ \\
\hline$-28(A>G)$ & $4.77 \%$ & $4.28 \%$ & $8.20 \%$ & $9.18 \%$ & $16.67 \%$ & $5.35 \%$ & $15.70 \%$ & $4.70 \%$ \\
\hline CD27/28(+ C) & $2.25 \%$ & $4.04 \%$ & $5.71 \%$ & $3.38 \%$ & $2.02 \%$ & $0.08 \%$ & $5.23 \%$ & $2.14 \%$ \\
\hline
\end{tabular}

Additionally, we identified a rare compound mutation, which is a combination of the IVS-I-130(G $>C)\left(\beta^{0}\right.$-thalassemia $)$ and IVS-II-81 $(\mathrm{C}>\mathrm{T})$ mutations. This causes minor thalassemia, which suggests that the IVS-II- $81(\mathrm{C}>\mathrm{T})$ mutation may be a silent mutation.

Besides, we identified two $\delta$-globin gene mutations, including $-77(\mathrm{~T}>\mathrm{C})$ and CD44 (TCC > TGC) (HBD:c.134C > G). Previous studies have shown that the $-77(\mathrm{~T}>\mathrm{C})$ mutation is the most common $\delta$-globin gene mutation in China (Liu et al., 2013; Chen M. et al., 2020) and may cause $\delta^{0}$ - or $\delta^{+}$-thalassemia. In our case, the $-77(\mathrm{~T}>\mathrm{C})$ mutation was combined with the $\mathrm{CD} 17(\mathrm{~A}>\mathrm{T})$ mutation, resulting in normal levels of $\mathrm{Hb} \mathrm{A} 2$ $(2.7 \%)$. This indicates that the diagnosis of $\beta$-thalassemia could be hindered when it is combined with $\delta$-thalassemia. Moreover, we made the first discovery in the Chinese population of the novel $\delta$-globin gene mutation CD44(TCC > TGC) (HBD:c.134C > G). The mutation at codon 44 , which results in $\mathrm{Ser} \rightarrow \mathrm{Cys}$ acid substitution, is believed to cause $\delta^{+}$-thalassemia.

We conducted an extensive analysis of the hemoglobinopathy spectrum for the subjects in our study and identified three types of hemoglobinopathies that were induced by an $\alpha$-globin gene mutation. Among them, Hb Q-Thailand ( $\alpha 74$ : Asp $\rightarrow$ His) has previously been reported in Chinese and other Southeast Asian populations. It is invariably linked to a leftward single $\alpha$-globin gene deletion $\left(-\alpha^{4.2}\right)$ and causes $\mathrm{Hb} \mathrm{Q}-\mathrm{H}$ disease when associated with $\alpha$-thalassemia (mainly _ ${ }^{S E A}$ ) (Hu et al., 2011; Zeng et al., 1992). Moreover, our study presented the first cases of Hb Owari ( $\alpha 121: \mathrm{Val} \rightarrow \mathrm{Met})$ in Fujian province, which was first identified in the Japanese population and exhibits normal functional properties (Harano et al., 1986). Additionally, we detected 37 cases of Hb New York, 12 cases of Hb J-Bangkok, and one case each of $\mathrm{Hb}$ Miyashiro and $\mathrm{Hb}$ G-Coushatta, all of which are induced by the $\beta$-globin gene mutation. We detected the first cases in the Quanzhou region of Hb New York, $\mathrm{Hb}$ J-Bangkok, and $\mathrm{Hb}$ G-Coushatta in this study. Previous studies indicated that co-inheritance of $\mathrm{Hb} \mathrm{New}$ York with three $\alpha$-globin gene deletions could lead to a severe $\mathrm{Hb} \mathrm{H}$ disease (Chan et al., 1987). In this study, we identified a male compound of $\mathrm{Hb}$ J-Bangkok and CD41-42(-TCTT). He exhibited normal hemoglobin values $\left(137 \times 10^{12} \mathrm{~g} / \mathrm{L}\right)$, low levels of $\mathrm{MCV}(56 \mathrm{fl})$ and $\mathrm{MCH}(18.3 \mathrm{pg})$, and increased $\mathrm{Hb}$ A2 (6.0\%). Our results were consistent with those of a previous study, which suggested that the coexistence of $\mathrm{Hb}$ J-Bangkok and $\beta$-thalassemia may not aggravate the phenotype (Zhao et al., 2013). Moreover, our study first identified the rare $\mathrm{Hb}$ Miyashiro mutation in the Chinese population. There is a GTT > GGT mutation at codon 23 in the $\beta$-globin gene, which can be detected by polyacrylamide gel isoelectric focusing (IEF) or reversed-phase high-performance liquid chromatography (HPLC) (Nakatsuji et al., 1981; Ohba et al., 1984). Therefore, we believe that it is essential to identify the hemoglobin variants in a population with a high prevalence of thalassemia in a routine setting.

A diverse range of rare thalassemia mutations was identified in this study, which is consistent with the location and the increasing population in Quanzhou prefecture. Notably, with thalassemia detection kits, we identified some rare thalassemia mutations that were more pervasive than the so-called common thalassemia mutations, such as CD31(-C), $-32(\mathrm{C}>\mathrm{A})$, and $-30(\mathrm{~T}>\mathrm{C})$, which have never been detected in this region before. Nowadays, next-generation sequencing is being increasingly used to improve thalassemia detection ( $\mathrm{He}$ et al., 2017; Zhao et al., 2020). Thus, DNA sequencing technology combined with gapPCR can detect all known and unknown mutations in the $\alpha$ - and $\beta$-globin gene in a cost-effective way, which will greatly reduce missed diagnoses. 


\section{CONCLUSION}

In this study, we conducted a comprehensive large-scale study on the thalassemia mutation in Quanzhou prefecture, which provides valuable data for the prevention and control of thalassemia. Our study is the first to reveal the spectrum of rare thalassemia mutations and hemoglobinopathies in the Quanzhou region. From this study, a diversity of rare thalassemia mutations and hemoglobinopathies was identified. This research, combined with the use of DNA sequencing and gap-PCR technology, shows great value in the investigation of rare and novel thalassemia gene mutations.

\section{DATA AVAILABILITY STATEMENT}

The raw data supporting the conclusions of this article will be made available by the authors, without undue reservation.

\section{ETHICS STATEMENT}

The studies involving human participants were reviewed and approved by the Ethics Committee of The Women's and Children's Hospital of Quanzhou (2020No.8). The

\section{REFERENCES}

Cao, P. J., Chen, L. Y., Jiang, L. L., Yang, Y., Chen, S. T., Huang, C. L., et al. (2019). [Analysis of Gene Mutation Types of Thalassemia in Fuzhou Area of China]. Zhongguo Shi Yan Xue Ye Xue Za Zhi. 27, 893-898.

Chan, V., Chan, T. K., Tso, S. C., and Todd, D. (1987). Combination of three alpha-globin gene loci deletions and hemoglobin New York results in a severe hemoglobin H syndrome. Am. J. Hematol. 24, 301-306. doi: 10.1002/ajh. 2830240310

Chen, M., Huang, H., Chen, L., Lin, N., Zhang, M., Lin, Y., et al. (2020). First report of the spectrum of $\delta$-globin gene mutations among women of reproductive age in Fujian area-Discrimination of $\delta$-thalassemia, $\alpha$-thalassemia, and Iron Deficiency Anemia. J. Clin. Lab. Anal. 34:e23479.

Chen, M. F., Huang, M. Z., Lin, Q., Huang, J., Chen, F., Zhang, J. Y., et al. (2020). [Analysis of the Types of Thalassemia Gene Mutations in Nanping Area of Fujian, China]. Zhongguo Shi Yan Xue Ye Xue Za Zhi. 28, 918-926.

Chen, T. P., Liu, T. C., Chang, C. S., Chang, J. G., Tsai, H. J., and Lin, S. F. (2002). PCR-based analysis of alpha-thalassemia in Southern Taiwan. Int. J. Hematol. 75, 277-280. doi: 10.1007/bf02982041

Dai, Q. F., Li, X. L., Wang, Y. X., and Cao, C. F. (2017). [Analysis of Gene Mutation Types of Thalassemia in Longyan Area of Fujian Province in China]. Zhongguo Shi Yan Xue Ye Xue Za Zhi. 25, 498-502.

Harano, T., Harano, K., and Ueda, S. (1986). Hb Owari [alpha 121 (H 4) Val--Met]: a new hemoglobin variant with a neutral-to-neutral amino acid substitution detected by isoelectric focusing. Hemoglobin 10, 127-134. doi: 10.3109/03630268609046439

He, J., Song, W., Yang, J., Lu, S., Yuan, Y., Guo, J., et al. (2017). Next-generation sequencing improves thalassemia carrier screening among premarital adults in a high prevalence population: the Dai nationality, China. Genet. Med. 19, 1022-1031. doi: 10.1038/gim.2016.218

He, S., Li, J., Li, D. M., Yi, S., Lu, X., Luo, Y., et al. (2018). Molecular characterization of $\alpha$ - and $\beta$-thalassemia in the Yulin region of Southern China. Gene 655, 61-64. doi: 10.1016/j.gene.2018.02.058

Hu, C., Zhang, L., Pan, J., Zeng, Z., Zhen, S., Fang, J., et al. (2011). Three cases of $\mathrm{Hb} \mathrm{Q}-\mathrm{H}$ disease found in a Cantonese family. Mol. Med. Rep. 4, 279-281. patients/participants provided their written informed consent to participate in this study.

\section{AUTHOR CONTRIBUTIONS}

JZ designed the study and wrote the article. NZ and JZ performed conventional thalassemia analysis. YZ performed specific gapPCR amplification and DNA sequencing. NZ and HZ analyzed the data. YX, YJ, DC, and YW revised and polished the manuscript. All authors have approved the final article.

\section{FUNDING}

This research was supported by the Quanzhou City Science and Technology Project (2020N049s).

\section{ACKNOWLEDGMENTS}

We wish to thank the subjects for agreeing to participate in this study. We would also like to express our appreciation to Quanzhou City Science and Technology Bureau for funding this work.

Huang, H., Xu, L., Chen, M., Lin, N., Xue, H., Chen, L., et al. (2019). Molecular characterization of thalassemia and hemoglobinopathy in Southeastern China. Sci. Rep. 9:3493.

Li, B., Zhang, X. Z., Yin, A. H., Zhao, Q. G., Wu, L., Ma, Y. Z., et al. (2014). High prevalence of thalassemia in migrant populations in Guangdong Province, China. BMC Public Health 14:905. doi: 10.1186/1471-2458-14-905

Liaska, A., Petrou, P., Georgakopoulos, C. D., Diamanti, R., Papaconstantinou, D., Kanakis, M. G., et al. (2016). $\beta$-Thalassemia and ocular implications: a systematic review. BMC Ophthalmol. 16:102. doi: 10.1186/s12886-016-0285-2

Lin, M., Zhong, T. Y., Chen, Y. G., Wang, J. Z., Wu, J. R., Lin, F., et al. (2014). Molecular epidemiological characterization and health burden of thalassemia in Jiangxi Province, P. R. China. PLoS One 9:e101505. doi: 10.1371/journal.pone. 0101505

Lin, Y. H., Lin, W., and Wang, X. X. (2019). [Genotyping of Patients with $\alpha$ and $\beta$ Thalassemia in Fujian Province Area in China]. Zhongguo Shi Yan Xue Ye Xue Za Zhi. 27, 899-903.

Liu, N., Xie, X. M., Zhou, J. Y., Li, R., Liao, C., and Li, D. Z. (2013). Analysis of $\delta$-globin gene mutations in the Chinese population. Hemoglobin 37, 85-93. doi: 10.3109/03630269.2012.747965

Liu, Q., Jia, Z. J., Xi, H., Liu, J., Peng, Y., and Wang, H. (2019). [Analysis on the Genotype of 5018 Cases of Thalassemia in Hunan Area]. Zhongguo Shi Yan Xue Ye Xue Za Zhi. 27, 1938-1942.

Lu, H., Qin, Q., Li, J. H., Chen, T., Liang, S. J., and Lu, X. S. (2021). [Genetic Diagnosis of Thalassemia in Baise, Guangxi Zhuang Autonomous Region]. Zhongguo Shi Yan Xue Ye Xue Za Zhi. 29, 865-868.

Ma, S. K., Chow, E. Y., Chan, A. Y., Kung, N. N., Waye, J. S., Chan, L. C., et al. (2000). beta-thalassemia intermedia caused by compound heterozygosity for Hb Malay (beta codon 19 AAC->AGC; asn-> Ser) and codons 41/42 (-CTTT) beta(0)-thalassemia mutation. Am. J. Hematol. 64, 206-209. doi: 10.1002/10968652(200007)64:3<206::aid-ajh12>3.0.co;2-\#

Modell, B., and Darlison, M. (2008). Global epidemiology of haemoglobin disorders and derived service indicators. Bull. World Health Organ. 86, 480487. doi: 10.2471/blt.06.036673

Nakatsuji, T., Miwa, S., Ohba, Y., Hattori, Y., Miyaji, T., Miyata, H., et al. (1981). Hemoglobin Miyashiro (beta 23[B5] val substituting for gly) 
an electrophoretically silent variant discovered by the isopropanol test. Hemoglobin 5, 653-666. doi: 10.3109/03630268108991833

Ohba, Y., Hattori, Y., Miyaji, T., Takasaki, M., Shirahama, M., Fujisawa, K., et al. (1984). Purification and properties of hemoglobin Miyashiro. Hemoglobin 8, 515-518. doi: 10.3109/03630268408991736

Vichinsky, E. P. (2013). Clinical manifestations of $\alpha$-thalassemia. Cold Spring Harb. Perspect. Med. 3:a011742. doi: 10.1101/cshperspect.a01 1742

Weatherall, D. J. (2001). Phenotype-genotype relationships in monogenic disease: lessons from the thalassaemias. Nat. Rev. Genet. 2, 245-255. doi: 10.1038/ 35066048

Weatherall, D. J. (2008). Hemoglobinopathies worldwide: present and future. Curr. Mol. Med. 8, 592-599. doi: 10.2174/156652408786241375

Xu, L. P., Huang, H. L., Wang, Y., Zheng, L., Wang, L. S., Xu, J. B., et al. (2013). [Molecular epidemiological analysis of $\alpha$ - and $\beta$-thalassemia in Fujian province]. Zhonghua Yi Xue Yi Chuan Xue Za Zhi. 30, 403-406.

Xu, X. M., Zhou, Y. Q., Luo, G. X., Liao, C., Zhou, M., Chen, P. Y., et al. (2004). The prevalence and spectrum of alpha and beta thalassaemia in Guangdong Province: implications for the future health burden and population screening. J. Clin. Pathol. 57, 517-522. doi: 10.1136/jcp.2003.014456

Yang, K. G., Kutlar, F., George, E., Wilson, J. B., Kutlar, A., Stoming, T. A., et al. (1989). Molecular characterization of beta-globin gene mutations in Malay patients with $\mathrm{Hb}$ E-beta-thalassaemia and thalassaemia major. Br. J. Haematol. 72, 73-80. doi: 10.1111/j.1365-2141.1989.tb07655.x

Yao, H., Chen, X., Lin, L., Wu, C., Fu, X., Wang, H., et al. (2014). The spectrum of $\alpha$ - and $\beta$-thalassemia mutations of the Li people in Hainan Province of China. Blood Cells Mol. Dis. 53, 16-20. doi: 10.1016/j.bcmd.2014.01.003

Yin, A., Li, B., Luo, M., Xu, L., Wu, L., Zhang, L., et al. (2014). The prevalence and molecular spectrum of $\alpha$ - and $\beta$-globin gene mutations in 14,332 families of Guangdong Province, China. PLoS One 9:e89855. doi: 10.1371/journal.pone. 0089855

Zeng, F. Y., Fucharoen, S., Huang, S. Z., and Rodgers, G. P. (1992). Hb Q-Thailand [alpha 74(EF3)Asp-> His]: gene organization, molecular structure, and DNA diagnosis. Hemoglobin 16, 481-491. doi: 10.3109/03630269208993 116

Zhang, C. M., Wang, Y., Gao, L. S., Gao, J. H., He, X. L., Feng, H. J., et al. (2010). Molecular epidemiology investigation of beta-thalassemia in Zhongshan City, Guangdong Province, People's Republic of China. Hemoglobin 34, 55-60. doi: $10.3109 / 03630260903547724$

Zhang, J., Zhu, B. S., He, J., Zeng, X. H., Su, J., Xu, X. H., et al. (2012). The spectrum of $\alpha$ - and $\beta$-thalassemia mutations in Yunnan Province of Southwestern China. Hemoglobin 36, 464-473. doi: 10.3109/03630269.2012.717327

Zhao, J., Li, J., Lai, Q., and Yu, Y. (2020). Combined use of gap-PCR and next-generation sequencing improves thalassaemia carrier screening among premarital adults in China. J. Clin. Pathol. 73, 488-492. doi: 10.1136/jclinpath2019-206339

Zhao, L., Qing, J., Liang, Y., and Chen, Z. (2016). A novel compound heterozygosity in Southern China: IVS-II-5 (G>C) and IVS-II-672 (A>C). Hemoglobin 40, 428-430. doi: 10.1080/03630269.2016.1252387

Zhao, Y., Shang, X., Xiong, F., Liu, Y. H., Lou, J. W., and Xu, X. M. (2013). [Analysis of clinical phenotypes of compound heterozygotes of Hb J-Bangkok and $\beta$-thalassemia]. Zhonghua Yi Xue Yi Chuan Xue Za Zhi. 30, 148-151.

Zheng, C. G., Liu, M., Du, J., Chen, K., Yang, Y., and Yang, Z. (2011). Molecular spectrum of $\alpha$ - and $\beta$-globin gene mutations detected in the population of Guangxi Zhuang Autonomous Region, People's Republic of China. Hemoglobin 35, 28-39. doi: 10.3109/03630269.2010.547429

Zhuang, J., Jiang, Y., Wang, Y., Zheng, Y., Zhuang, Q., Wang, J., et al. (2020a). Molecular analysis of $\alpha$-thalassemia and $\beta$-thalassemia in Quanzhou region Southeast China. J. Clin. Pathol. 73, 278-282. doi: 10.1136/jclinpath-2019206179

Zhuang, J., Tian, J., Wei, J., Zheng, Y., Zhuang, Q., Wang, Y., et al. (2019). Molecular analysis of a large novel deletion causing $\alpha^{+}$-thalassemia. BMC Med. Genet. 20:74. doi: 10.1186/s12881-019-0797-8

Zhuang, J., Zheng, Y., Wang, Y., Zhuang, Q., Jiang, Y., Xie, Q., et al. (2020b). Identification of a new $\beta$-thalassaemia variant Term CD+32(HBB: c.32A >C) in two Chinese families. J. Clin. Pathol. 73, 593-596. doi: 10.1136/jclinpath2020-206426

Conflict of Interest: YZ was employed by the company Yaneng BIOscience (Shenzhen) Co., Ltd.

The remaining authors declare that the research was conducted in the absence of any commercial or financial relationships that could be construed as a potential conflict of interest.

Publisher's Note: All claims expressed in this article are solely those of the authors and do not necessarily represent those of their affiliated organizations, or those of the publisher, the editors and the reviewers. Any product that may be evaluated in this article, or claim that may be made by its manufacturer, is not guaranteed or endorsed by the publisher.

Copyright (c) 2021 Zhuang, Zhang, Wang, Zhang, Zheng, Jiang, Xie and Chen. This is an open-access article distributed under the terms of the Creative Commons Attribution License (CC BY). The use, distribution or reproduction in other forums is permitted, provided the original author(s) and the copyright owner(s) are credited and that the original publication in this journal is cited, in accordance with accepted academic practice. No use, distribution or reproduction is permitted which does not comply with these terms. 